\section{Visión Electrónica Más que un estado sólido \\ https://doi.org/10.14483/issn.2248-4728}

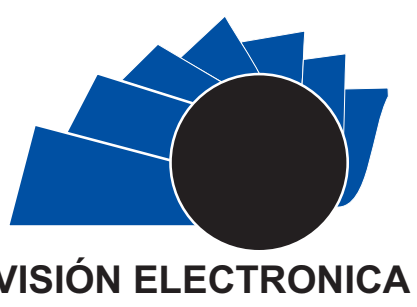

A Research Vision

\title{
EXPRO: exoskeleton for rehabilitation of upper limb
}

\author{
EXPRO: exoesqueleto para rehabilitación de miembro superior
}

Javier Fernando Garnica-Molina ${ }^{1}$, Juan Nicolás Bustos-Ramírez ${ }^{2}$, Jessica Zuleima Parrado-Agudelo ${ }^{3}$, Cristian Mauricio ${ }^{4}$, Casallas-Contreras ${ }^{5}$, Luis Miguel Méndez-Moreno ${ }^{5}$

INFORMACIÓN DEL ARTICULO

Historia del Articulo

Enviado: 27/10/2018

Recibido: 09/11/2018

Aceptado: 13/12/2018

\section{Keywords:}

Biomedical,

Exoskeleton,

Rehabilitation,

Therapy,

Upper limb.

\section{Palabras clave:}

Biomédica,

Exoesqueleto,

Rehabilitación,

Terapia,

Extremidades.

\section{ABSTRACT}

In the upper limb rehabilitation field, assisting to various patients per day, in different kinds of therapies is an exhausting task which can be achieved in a semiautomated or automated manner. The ExPro is an exoskeleton of 3 degrees of freedom designed and created to support rehabilitation treatments for patients with little or no mobility in their arms. The device consists in a machine able to move forearm and wrist according to prone-supination, ulnar and radial deflection and flex-extension of wrist movements. The proposed prototype was designed to assist therapists in the first step of rehabilitation treatments, thus, passive therapies. Each mechanical component was designed in the Inventor 3D software and printed on PLA materials (polylactic acid). The controlling step is a Raspberry Pi 3 that receives information, interprets and connects power, and control PCBs. The design and calculations were tasted with the finite elements tool of inventor software. The work result presents an exoskeleton prototype easy to operate and transport, safe for the patient and able to carry out several preprogramed movements.

\section{RESUMEN:}

En el campo de la rehabilitación, asistir a varios pacientes por día en diferentes tipos de terapias es una tarea extenuante que puede ser llevada a cabo de manera semiautomatizado o automatizada. El ExPro es un exoesqueleto de tres grados de libertad diseñado y construido para asistir tratamientos de rehabilitación en pacientes con poca o nula movilidad en sus brazos. El dispositivo consiste en una máquina capaz de mover el antebrazo y la muñeca acorde a los movimientos de pronosupinación, flexión ulnar y radial y flexo-extensión de muñeca.

\footnotetext{
${ }^{1}$ BSc.(c)InMechatronicsEngineering,UniversidadNacionaldeColombia,Colombia.E-mail: jfgarnicam@unal.edu.co ORCID: https://orcid.org/0000-0001-6570-1391 2 BSc. (c) In Mechatronics Engineering, Universidad Nacional de Colombia, Colombia. E-mail: jnbustosr@unal.edu.co ORCID: https://orcid.org/0000-0002-7661-2738 ${ }^{3}$ BSc. (c) In Mechanics Engineering, Universidad Nacional de Colombia, Colombia. E-mail: izparradoa@unal.edu.co ORCID: https://orcid.org/0000-0002-7748-6630 ${ }^{4}$ BSc. (c) In Mechanics Engineering, Universidad Nacional de Colombia, Colombia. E-mail: cmcasallasc@unal.edu.co ORCID: https://orcid.org/0000-0002-6864-0173 ${ }^{5}$ BSc. In Mechanics Engineering, Universidad de los Andes, Colombia. MSc. In Mechanics engineering, Universidad de los Andes, Colombia. PhD. In Science and technology of materials, Universidad Nacional de Colombia, Colombia. E-mail: lmmendezm@unal.edu.co ORCID: https:/ orcid.org/o0o0-0001-5437-2211
} 


\section{Introduction}

According to the ONU convention (2006), disability is defined as the result of the interaction between people with impairments and barriers due to the attitude or environment where their full participation on an equal footing is hindered. Then disability is understood as deficiencies both physical and mental [1]. The number of people with some way of disability exceeds globally one billion, which is $15 \%$ of the world population. From this percentage, 200 people have considerable difficulties in operation and, even more alarming, it is an increasing trend since the population is aging and disability risk is higher in older ages [2]. Neuromuscular damage, muscular atrophy and muscular dystrophy are the main factors of the decreased muscle strength [3] in addition to neurological disorder as Guillain Barre, which generates progressive paralysis in several muscles of the body [4].

To recover mobility of limbs, active and passive therapies are performed. In an active therapy, the therapist attends it only in certain therapy moments [5]. Whereas, in a passive therapy, the patient cannot move its extremities, thus the professional must move them in the entire therapy the patient can move its extremities in a limited way [5]. Assisting to various patients per day, in several therapies is an exhausting task. Some devices such as elastic resistance bands, specialized mechanisms, and exoskeletons are utilized to facilitate and to make more efficient this labour. The use of exoskeletons represents a considerable advance in the rehabilitation field [6]. Its structure, functioning and new technologies use range from pneumatic actuators [7], electric actuators [8-11] and virtual reality tools [12-13].

This document describes the design and construction of an exoskeleton prototype of three degrees of freedom (DoF). This machine moves the arm according to three different couple of movements: pronesupination, ulnar and radial deflection and flexextension of the wrist. The first step in the design of the device was the determination of the issues to be addressed in the area of rehabilitation. Then, a solution is proposed, carried out and tested as this paper report.

\section{Methods}

The first step in the design of the device was the determination of the issues to be addressed in the area of rehabilitation. A therapist (physical or occupational) attends to 20 patients on an average day. The anatomy of these patients and the requirement of therapies represent a considerable physical effort for these professionals. For this reason, the design and construction of a device is proposed to assist therapists during the process of passive rehabilitation of upper limb.

After determining the problem, the state of art is reviewed regarding machines and / or devices that play the role of assistance in rehabilitation of upper limbs. For example, Soft-Actuated is an exoskeleton of seven degrees of freedom, which implements pneumatic muscles [3]. BLEEX (Berkeley Lower Extremity Exoskeleton) uses a control architecture network (ExoNET) to provide the physical network where the control algorithms run [4]. ASSIST [5] (Active Support Splint) is an exoskeleton of one degree of freedom that is driven by soft pneumatic actuators, among other devices.

Then, the requirements of the device are defined under the guidance of the occupational therapist Silvia Duarte and the MSc. Mechanics engineer Luis Miguel Mendez, both professors at the Universidad Nacional de Colombia. The requirements defined are the following:

- Safety, the device should not cause any injury to the patient.

- Transportability, its movement should be performed easily.

- Easy operation, making use of the device should be a task without difficulty.

After evaluating the requirements and based on the state of the art, the engineering level requirements necessary for operation of the device are listed, such as construction materials, electronics and computational tools, software development, among others. From this point, the work of Protos-UN was divided into three groups. First, the mechanics group was in charge of the mechanical design calculations and the related forces and velocities, as well as of the material selection and assembly of the device. Second, the electronics group managed the control device, the selection of actuators and power feeding elements and the design of PCBs. Finally, the group HMI (Human Machine Interface) was responsible for the selection of software development, design of graphical interface programming, control routines, and communication between HMI and control circuits.

Following the creation of the groups, the hard work of design and construction began, framed in an iterative design process. Then, the main methods used are listed below: 
- Additive manufacturing (3D printing): Used for the construction of some parts of the device, such as gears, mountings, motor brackets and other joints between segments.

- Manufacturing processes: Laser cutting, drilling and milling, required for the machining of some parts.

- Programming: Coding of each of the control routines of the display elements (pilots), actuators (servomotors) and communication (between the HMI and circuits).

- Assembly: Both the device holder elements and the union of each of the electronic parts and the interaction among HMI, circuits and actuators.

\section{Results and Discussion}

The first ExPro prototype was developed in six months. Currently, it consists in a system capable of rehabilitating three degrees of freedom of the upper limb, reflected in the movements of elbow pronation and supination, wrist flexion and extension, and ulnar and radial wrist deviation. When activating three servomotors, the necessary movements for muscle rehabilitation process are executed. In addition, the device allows to select and define the therapy (selecting the angular limits of each of the six movements) with a computer application that sends the information to the main control device: A Raspberry Pi 3. Raspberry translates that information into commands to drive the servo motors and generate the selected movements. As mentioned earlier, the development of the devices consists of three major sections, thus, the results are presented according to those sections.

At electronic level, two PCBs were developed, one responsible for feeding power to three servomotors, four indicators pilots, a buzzer, cooling elements, the Raspberry $\mathrm{Pi}$ and other electronic components; the second $\mathrm{PCB}$ oversees control device whose main function is to communicate with the HMI actuators, following user commands.

Mechanically, the first step was to define the speeds and torques for each of the motors. Therefore, the device is programmed to operate at a constant speed determined previously by testing. Moreover, the device is designed to support the weight and being able to move the arm of a person $100 \mathrm{~kg}$. As stated earlier, the exoskeleton has three degrees of freedom, based on this, performs therapeutic movement as hereinafter described.

Frist degree of freedom: Ulnar-radial wrist deviation.

This movement of rotation is generated from the first servomotor which is located on the side as shown in
Figure 1. Through the piece of the handle, the torque is transmitted to the hand, generating the movement presented in Figure 2, with maximum twenty degrees for radial deviation and a maximum of thirty degrees for ulnar deviation.

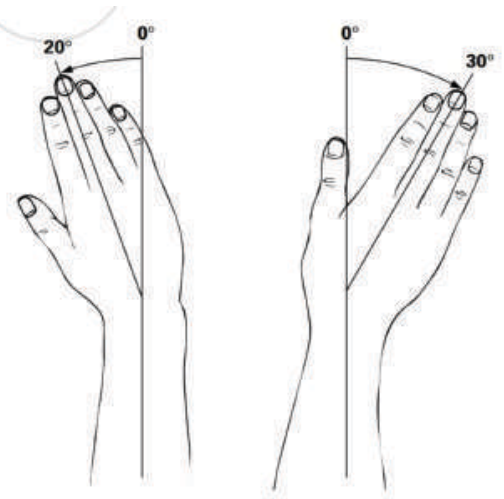

Figure 1. Radial Deviation (left) and Ulnar Deviation (right) angles of Right Wrist. Opposite denomination and angles for the Left Wrist, [14].

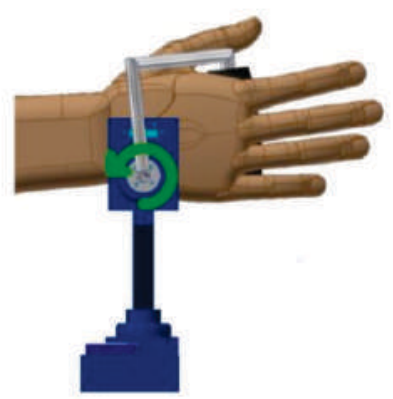

Figure 2. First servomotor location. Source: own.

Second degree of freedom: Wrist flexion and extension By means of the second servomotor, located in the center of the Figure 3, under the wired wrist, a rotational movement generates a range of $120^{\circ}$, uniformly distributed for both wrist flexion and wrist extension movements, as shown in Figure 4. Through the support part movement is transmitted to the base that support the first servomotor and the handle, turning the hand, whereby the flexo-extension movement expected is obtained.

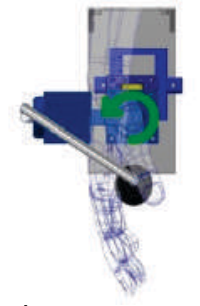

Figure 3. Second servomotor location. Source: own. 


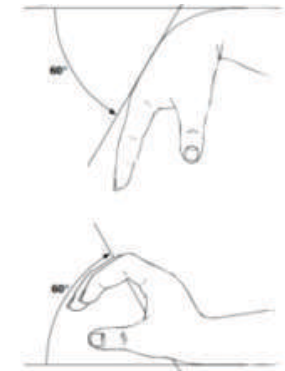

Figure 4. Wrist Flexion (above) and Extension (below) angles, [14].

Third degree of freedom: Forearm pronosupination. Using a third servomotor the rotation movement must comprise a range of $160^{\circ}$ uniformly distributed as can be seen in Figure 5. The pinion mounted on the servomotor transmits power to the gear, this gear is mounted entire structure leading to the wrist. For this reason, moving the gear, the entire structure of the wrist joint moves him, finally producing the movement of pronosupination, presented in Figure 6.

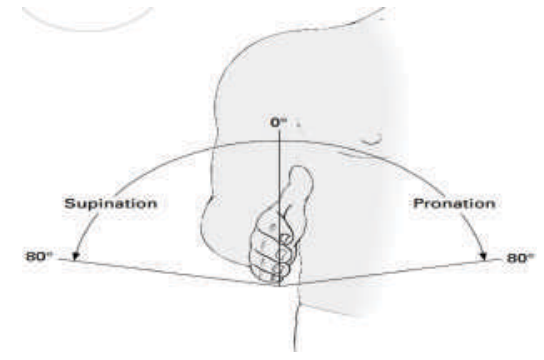

Figure 5. Pronation and Supination angles of Forearm, [14].

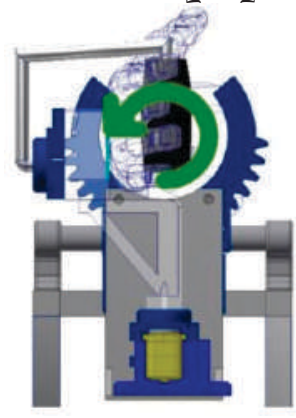

Figure 6. Third servomotor location. Source: own.

Calculation gear (Crown + Pinion) methodology AGMA. In the first instance the transmission ratio (2) defined, and module to be implemented $(\mathrm{m}=4)$, this module was selected due to the manufacturing process implemented for the gear, $3 \mathrm{D}$ printing, and $20^{\circ}$ pressure angle. With this set, and the torque and working speeds, the geometry of the pinion and crown defined.

\begin{tabular}{|c|c|c|}
\hline STRAIGHT GEAR & Pinion & Crown gear \\
\hline $\mathrm{N}$ [Number of teeth] & 18 & 36 \\
\hline X [Speed ratio] & 1 & 2 \\
\hline Normal pressure angle [ $\left.{ }^{\circ}\right]$ & 20 & 20 \\
\hline Step diametral Pn [teeth $/ \mathrm{mm}]$ & 0.25 & 0.25 \\
\hline Pitch diameter d [mm] & 72 & 144 \\
\hline Tooth thickness "t" [mm] & 6.3 & 6.3 \\
\hline Face width F & \multicolumn{2}{|c|}{17.59} \\
\hline
\end{tabular}

Table 1. Geometry pinion-crown gear Source: own.

\section{Calculation bending stress AGMA}

In the first place, the stress supported by the gear was calculated and compared with the allowable stress of the material. In this case, the Nylon stress was used to compare and a correction factor was added. This factor was used to contemplate that another material (PLA) with different mechanical properties was implemented. Finally, the safety factors that have for flexion are determined.

\begin{tabular}{|c|c|}
\hline Bending strength material [Mpa] & 48 \\
\hline Bending allowable stress [kgf / mm 2] & 1.5 \\
\hline Bending allowable stress [MPa] & 147.105 \\
\hline Correction factor for printing and materials & 0.8 \\
\hline Bending allowable stress Material [Mpa] & 117.684 \\
\hline N cycles pinion & 100.000 \\
\hline Allowable stress fixed [Mpa] & 25 \\
\hline Bending safety factor & 6.29 (pinion) \\
& 6.98 (gear) \\
\hline
\end{tabular}

Table 2. Bending stress. Source: own.

\begin{tabular}{|c|c|}
\hline Contact allowable stress [MPa] & 245.175 \\
\hline N. cycles Pinion & 100.000 \\
\hline Allowable stress Fixed [Mpa] & 30.481 \\
\hline Contact safety factor & 1.5 \\
\hline
\end{tabular}

Table 3. Contact stress. Source: own.

Additionally, through the finite element analysis tool of the inventor software, the stresses and deformations on the critical parts of the device were evaluated. First, the gear and pinion of the pronosupination section were evaluated. When analyzing the stresses in the crown gear, it is observed that the greatest stress occurs in the root of the tooth. However, the maximum stress does not exceed the allowable stress of the material (printed PLA $28 \mathrm{Mpa})$.

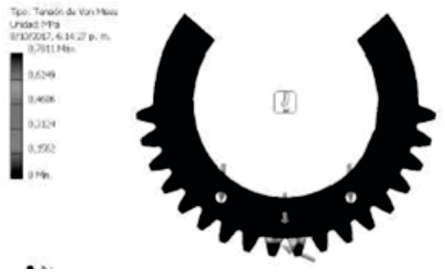

Figure 7. Distribution of stresses - Main Gear. Source: own. 


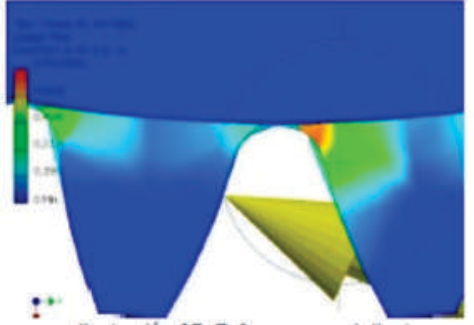

Figure 8. Stress in the tooth. Source: own.

Displacements and deformations. As to displacements, the tip of the tooth is the one that is most affected having the greatest displacements. The maximum displacement is $0.1069 \mathrm{~mm}$, considering the magnitude of the displacement and the stress analysis previously presented, the deformation presented in the tooth is considered negligible.
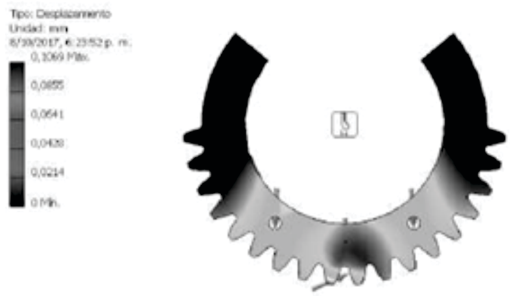

Figure 9. Displacements and deformations. Source: own.

Pinion. The pinion of the pronosupination mechanism was also analyzed for stresses and deformations by the finite element analysis tool of the inventor software. In this case, the greatest efforts are observed near the shaft hole, due to the presence of the holes for the coupling to the motor. These holes act as concentrators of efforts and generate maximum efforts in this area. However, the maximum stress $(1.6 \mathrm{MPa})$ is well below the allowable material stress $(28 \mathrm{MPa})$.

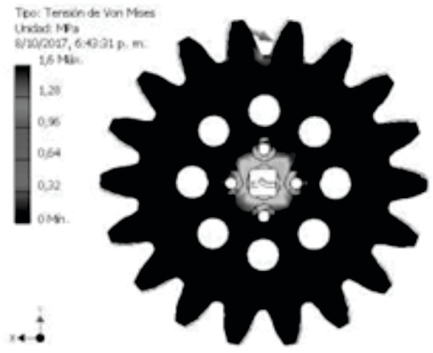

Figure 10. Efforts on the pinion. Source: own.

Moreover, in terms of displacements, it appears that the pinion tooth major deformation occurs, but this maximum deformation is $0.6898 \mathrm{~mm}$.

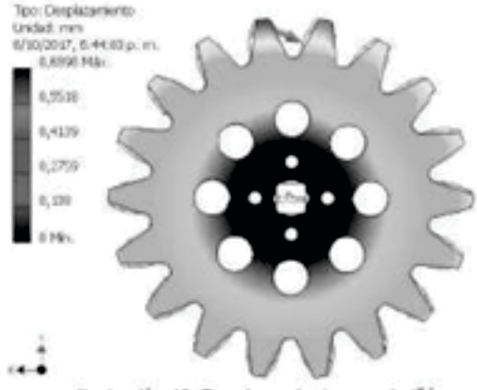

Figure 11. Displacements on the pinion. Source: own.

Calculations associated with doll:

In the case of the wrist, there are two mechanisms in charge of the flexo-extension movements and the ulnar-radial deviation of the wrist. The pieces of these mechanisms were evaluated using the finite element tool in the software Inventor of Autodesk.

Cantilevered Support:
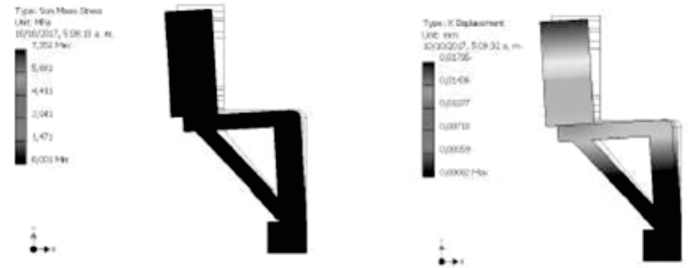

Figure 12. Cantilevered Source: own.

The maximum effort obtained is 7,352 Mpa, rather less than the allowable stress of the material $(28 \mathrm{MPa})$. The maximum displacement was about $0.018 \mathrm{~mm}$, which is negligible compared to the measures of the mechanism.

Support Command:

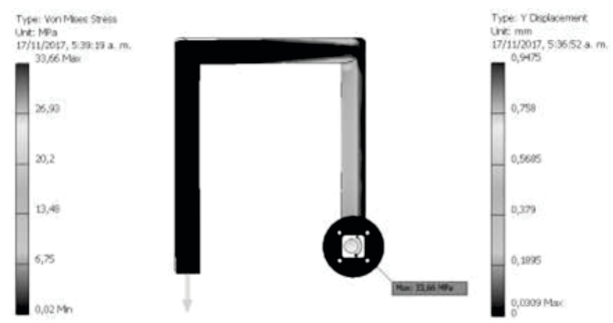

Figure 13. Support Command. Source: own.

The maximum effort obtained is 33,6 Mpa, rather less than the allowable stress of the material $(255 \mathrm{MPa})$. The maximum displacement was about $1 \mathrm{~mm}$, which is allowable within performance requirements.

This part is used in two different provisions therefore must be analyzed in two different directions with their restrictions. 

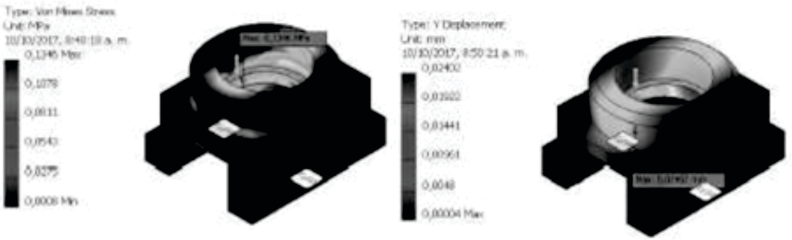

Figure 14. Bearing Support - Provision 1. Source: own.

The maximum effort obtained is $0,135 \mathrm{Mpa}$, rather less than the allowable stress of the material $(28 \mathrm{MPa})$. The maximum displacement was about $0.024 \mathrm{~mm}$, which is non-representative compared to the measures of the mechanism.

Configuration 2. The maximum stress obtained is 0,143 $\mathrm{Mpa}$, rather less than the allowable stress of the material $(28 \mathrm{MPa})$. The maximum displacement was about $0.012 \mathrm{~mm}$, which is non-representative compared to the measures of the mechanism.
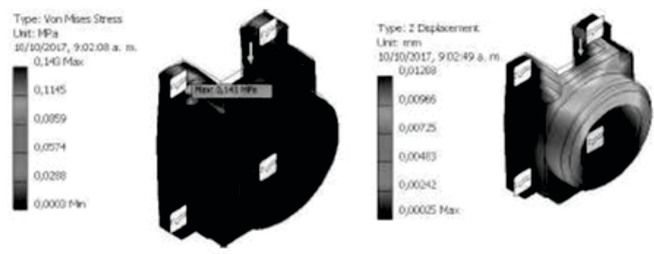

Figure 15. Bearing Support - Configuration 2. Source: own.

Figure 16 shows the finished device:

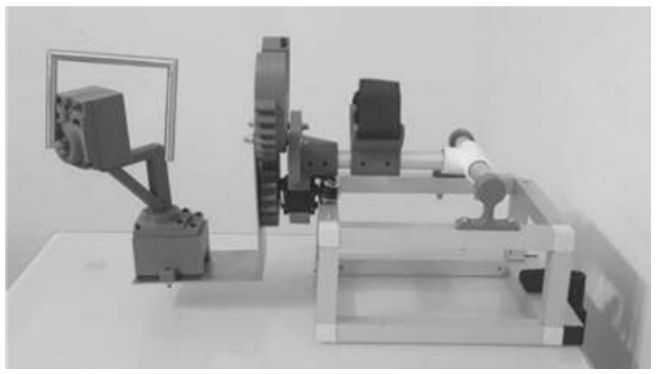

Figure 16. Mechanically I ExPro. Source: own.

A future it's plans to add more degrees of freedom to ExPro, such as flexion and extension of the elbow, also, it's proposed to the future, a new anchoring system device where this is sufficiently portable to put it on any table or surface to facilitate the approach of therapies to people prostrated or in some other disability situation. Apart from these improvements, there are plans to convert the application, which is currently computer, a mobile application, for cellular or tablets operating with android operating system to communicate directly with the Raspberry Pi in the electrical device housing.

\section{Conclusions}

-The implementation of the exoskeleton designed (ExPro) in rehabilitation works will be a helpful tool to optimize the work done by professionals in the field of rehabilitation by reducing the effort required to assist each patient and controlled through software the therapies to make.

-In order to improve the user experience by the user, there must be implemented devices to facilitate handling of the device; therefore, the initiative to use mobile applications such as control of the exoskeleton is a wise solution.

-The use of these kinds of devices is a support to therapeutic exercise and a strategy of improvement and innovation to their tasks; they are not intended to replace the therapist in his role as a specialist.

-In a future, it plans to add more degrees of freedom to ExPro, such as flexion and extension of the elbow, also, it is proposed to the future, a new anchoring system device where this is sufficiently portable to put it on any table or surface to facilitate the approach of therapies to people prostrated or in some other disability situation. Apart from these improvements, there are plans to convert the application, which is currently computer, a mobile application, for cellular or tablets operating with android operating system to communicate directly with the Raspberry $\mathrm{Pi}$ in the electrical device housing

\section{Acknowledgments}

Product developed by a multidisciplinary team of electronics, mechatronics, mechanics engineering and medicine students, called Protos-UN, with economic support of the "Programa Grupos de Trabajo, Universidad Nacional de Colombia".

PROFESSOR ADVISOR: Msc. Luis Miguel Méndez. OCCUPATIONAL THERAPIST ADVISOR: Silvia Duarte. MEMBERS: Fernando Garnica, Nicolás Bustos, Jessica Parrado, Cristian Casallas, Juan Pablo Flórez, David Palencia, Elizabeth López, Camilo García, Daniela Becerra, Juliana Orjuela, Julián Hernández, Diego Flórez, Andrés Oriegón, Carolina Cruz, Felipe Rojas, Leonardo Mercado, Gisela Ferrer.

\section{References}

[1] World Health Organization, "International Classification of Impairments, Disabilities and Handicaps", 1980. [Online]. Available at:https://apps.who.int/iris/bitstream/handle/ 10665/41003/9241541261_eng.pdf?sequen $\underline{\mathrm{ce}}=1$ \&isAllowed $=\mathrm{y}$ 
[2] Departamento Administrativo Nacional de Estadística (DANE), "Información estadística de la discapacidad", 2004. [Online]. Available at:

https://www.dane.gov.co/files/investigacione s/discapacidad/inform estad.pdf.

[3] D. A. Tibaduiza, J. Grosso, N. Chio and M. Anaya, "Diseño de un Exoesqueleto Mecatrónico de Brazo Basado en Screws y Robots Paralelos", Congreso Internacional de Ingeniería Mecatrónica - UNAB, vol. 1, 2009.

[4] Z. Gao, X. Li, T. Peng, Z. Hu, J. Liu, J. Zhen and Y. Gao, "Systemic lupus erythematosus with Guillian-Barre síndrome”, Medicine, vol. 97, no. 25,2018 .

https://doi.org/10.1097/MD.0000000000011 160

[5] J. F. Ayala, et al., "Mechanical design of an exoskeleton for upper limb rehabilitation", Revista Colombiana de Biotecnología, vol.17, no. 1, 2015 .

http://dx.doi.org/10.15446/rev.colomb.biote. v17n 1.44188

[6] G. Kwakkel, B. J. Kollen and H. I. Krebs, "Effects of robot-assisted therapy on upper limb recovery after stroke: a systematic review", Neurorehabilitation neural repair, vol. 22, no. 2, 2008, pp. 111-121.

https://doi.org/10.1177/1545968307305457

[7] D. Sasaki, T. Noritsugu and M. Takaiwa, "Development of active support splint driven by pneumatic soft actuator (ASSIST)", IEEE International Conference on Robotics and Automation, 2005, pp. 520-525. https://doi.org/10.1109/ROBOT.2005.15701 $\underline{71}$

[8] R. Gutiérrez, P. Niño, O. Avilés, F. Vanegas and J. Duque, "Exoesqueleto Mecatrónico Para Rehabilitación Motora", 8vo CONGRESO IBEROAMERICANO DE INGENIERÍA MECÁNICA, 2007.

[9] A. Sledd and M. K. O'Malley, "Performance enhancement of a haptic arm exoskeleton", 14th Symposium on Haptic Interfaces for Virtual Environment and Teleoperator Sys tems, 2006 , p p. $375-381$. https://doi.org/10.1109/HAPTIC.2006.1627 $\underline{127}$
[10] K. Kiguchi, "Active exoskeletons for upper-limb motion assist", International Journal

Humanoid Robotics, vol. 4, no. 3, 2007, pp. 607-624.

https://doi.org/10.1142/S0219843607001175

[11] J. Perry, J. Rosen and S. Burns, "Upper limb powered exoskeleton design”, IEEE/ASME Transactions on Mechatronics, vol. 12, no. 4, 2007, p p. $408-417$. https://doi.org/10.1109/TMECH.2007.9019 $\underline{34}$

[12] W. Chou, T. Wang and J. Xiao, "Haptic interaction with virtual environment using an arm type exoskeleton device", IEEE International Conference on Robotics and Automation, 2004, pp. 1992-1997. https://doi.org/10.1109/ROBOT.2004.13081 $\underline{16}$

[13] T. Nef, M. Mihelj and R. Riener, "ARMin: a robot for patient-cooperative arm therapy", Medical \& biological engineering \& computing, 2007. https://doi.org/10.1007/s115170070226-6

[14] S. J. Lord and L. Cocchiarella, "Master the AMA Guides Fifth: A Medical and Legal Transition to the Guides to the Evaluation of Permanent Impairment", Fifth Edition, AMA Press, 2001. 